\title{
Arguments for Nonparental Care for Children
}

\author{
"It takes a village to raise a child" (African proverb) \\ "Only those who do not work do not make mistakes" (Romanian proverb)
}

The value of nonparental childcare is a widely debated issue. Although in many contemporary societies most children are exposed to some nonparental care carried out either in various institutions or by nannies, friends, and extended families, people disagree about its benefits - especially for preschool children - and few believe there is a duty to ensure that all children are exposed to it. The law usually allows parents to exclude children of preschool age from nonparental care, and where homeschooling is allowed, nonparental care can be avoided for much longer. Here, I criticize the still widespread conviction that there is nothing wrong in confining childcare to parents. Moreover, I argue that there is a duty to ensure that care for all children older than one be shared between parents and people who come into children's lives as strangers but who are prepared and willing to develop caring relationships with them. By "parents” I mean the primary figures in children's lives, those who take the moral and legal responsibility for caring continuously for children until they reach maturity. ${ }^{1}$ By "nonparental care" I mean care given by people who are not the parents of the children for whom they care but who may be other children's parents.

I outline three arguments already present in the literature on childcare and then introduce five more arguments that discuss the value of exposing all children older than one to some nonparental care. To the best of my knowledge, with the exception of argument 5, the arguments discussed in section 4 have not been formulated as such before. ${ }^{2}$

\footnotetext{
${ }^{1}$ The parents may be biological or not, single or partnered, married (to each other) or not, gay or heterosexual; I do not discuss how different types of family may impact on childrearing. The only assumption I make is that children need to have at least one adult committed to providing continuous care and thus serving as a primary figure, and that societies should ensure that this need is met.

${ }^{2}$ Arguments 4,7 , and 8 rely on feminist work on the various ways in which childcarers can fail to give adequate care. While many of the cited authors would support nonparental care (as a universally available, if not mandatory, institution), they have not 
Some of the arguments are based on the well-being of children and/or parents, others on fairness (towards children and/or parents, and towards mothers) and some on both well-being and fairness. Argument 6 concludes that nonparental childcare is a matter of duty towards children, resulting from their dependence on caregivers. While some of the arguments show that nonparental care is highly desirable, others have the more radical implication that excluding children from nonparental care is morally wrong, with the ultimate conclusion being that parents do not have the right to exclude their children from nonparental care. Although there are different grounds for the different arguments I discuss-wellbeing, fairness, and duty - I hope that, taken together, they support each other in making the case for a system of universal, compulsory, and state-regulated childcare similar to the existing system of universal compulsory education. I refer to this as "universal nonparental care."

Although much of my argument rests on the importance of fairness towards children, on the endemic nature of mistakes in care and on children's vulnerability to failed care, I shall not consider the more radical possibilities of addressing these issues by either abolishing the family and raising children in well-run orphanages or by instituting a parenting license scheme. ${ }^{3}$ Instead, I start from the assumption that parenting as we know it ${ }^{4}$ is valuable and worth preserving, as long as parents do not do all the childcare.

elaborated on the connection between inadequate care and the importance of nonparental care. Robert Goodin, on whose theory of vulnerability I ground argument 6 , has written about family relationships and childrearing. See, for example, Protecting the Vulnerable (Chicago: Chicago University Press, 1985), and "Responsibilities for Children's WellBeing," in Sue Richardson and Margot Prior (eds.), The Well-Being of Australia's Children (Carlton, Vic.: Melbourne University Press, 2005), pp. 60-82. However, Goodin has not applied his argument concerning unacceptable monopolies in order to show that parent-child relationships involve a morally objectionable form of vulnerability unless nonparental carers are regular and robust suppliers of childcare.

${ }^{3}$ For a discussion of the first solution, see Véronique Munoz-Dardé, "Is the Family to be Abolished Then?" in Proceedings of the Aristotelian Society 99 (1999): 37-56. I think children's need for a continuous and highly personalized bond of care and the importance adults place on parenting rule out the universal orphanage option. The parent licensing scheme has been advocated by Hugh LaFollette, "Licensing Parents," Philosophy \& Public Affairs 9 (1980): 182-97, and widely—and sympathetically—explored by Harry Adams in his Justice for Children: Autonomy, Development and the State (Albany: State University of New York Press, 2008). I believe the intrusion into people's privacy involved in a licensing scheme would be exceedingly damaging to individual freedom and to interpersonal relationships. For convincing criticism, see Daniel Engster, "The Place of Parenting within a Liberal Theory of Justice: The Private Parenting Model, Parental Licenses, or Public Parental Support?” Social Theory and Practice 36 (2010): 233-62.

${ }^{4}$ That is, a practice that involves one or several adults being the main caregivers of their children, whom they have come to parent sometimes intentionally and sometimes by accident. 
The effects of nonparental care, and especially of institutional care, ${ }^{5}$ on children have an important bearing on their overall desirability. It is difficult to assess the evidence, not only because some the available data are contradictory (and often research on childcare is ideologically driven), but also because much of the existing institutional childcare is deficient and thus adequate empirical evidence is very difficult to gather. These difficulties aside, after a thorough assessment of the literature on childcare in the U.S., Jane Waldfogel has recently concluded that while nonparental childcare during their first year might be harmful to children, nonparental care of children after their first year appears to be neutral or even beneficial. ${ }^{6}$ Obviously, nonparental care must meet certain minimal criteria. Based on recent research on the effects of institutional childcare, Daniel Engster concludes that it "generally appears that nonparental childcare arrangements are not harmful for most children as long as they meet various quality measures including low adult-child ratios, adequate levels of caregiver training, staff stability, and decent physical facilities."7

Since I make a generic case for nonparental care, I do not specify details such as the best ratio of parental to nonparental care. The precise content of desirable nonparental care will vary with children's individual needs, which are partially determined by age. In practice, exposing all children older than one to some nonparental care could mean, for example, that they spend a few hours every day in childcare institutions. Nonparental care can take the form of day care for infants, kindergartens for preschool children, and school and after-school activities for older children.

\section{Nonparental Care and Justice}

The discussion of universal nonparental care involves three distinct, yet very closely related, questions. Only the first of these-about the value of nonparental care-is fully addressed in this article. The other two questions are: Should nonparental care necessarily be provided by professionally trained people and, if so, should it be provided in state-

\footnotetext{
${ }^{5}$ Many societies have histories of particularly bad institutional care. In these cases, people have the understandable perception that care given in institutional settings is necessarily inferior to family care and often unacceptably bad. See Kathleen Lynch, John Baker, and Maureen Lyons (eds.), Affective Equality: Love, Care and Injustice (London: Palgrave, 2009).

${ }^{6}$ See Jane Waldfogel, What Children Need (Cambridge, Mass.: Harvard University Press, 2006). I am grateful to Daniel Engster for drawing my attention to this book.

${ }^{7}$ See Daniel Engster, The Heart of Justice (Oxford: Oxford University Press, 2007), p. 214.
} 
regulated institutions or in private settings? and, Who should bear its costs: parents, society, or a combination of both? While I cannot engage at length with the last two questions, some of the arguments I discuss suggest that nonparental care should be provided by professional caregivers in state-regulated institutions.

In the context of establishing whether justice requires universal nonparental care, the more difficult question is whether the costs of childcare should be at least partly borne by society. There are several reasons why all the members of society should share the burdens of raising children ${ }^{8}$ but they are highly disputed, ${ }^{9}$ and it is beyond the scope of this paper to make the case in favor of this position. For those not convinced that justice requires us to share the costs of childcare, arguments 3,7 , and 8 will be arguments about parental well-being rather than arguments concerning fairness towards parents. Most arguments will, however, be unaffected by the answer to the question whether childless people should bear the costs of nonparental care. State-regulated childcare institutions, or other forms of organized nonparental care, could be funded by parents only, for example, through a tax not payable by childless people. In this paper, I remain agnostic on this issue, but I point out its relevance for particular arguments.

I assume there are several, sometimes divergent, considerations that determine what is, overall, just; these include fairness, needs, rights, duties, and utility. ${ }^{10}$ The relevant considerations for judging that universal nonparental care is just that I discuss here are children's and parents' needs, fairness, and a general duty to protect children from unacceptable forms of dependency. I believe that, taken together, these arguments show that parents do not have the moral right to exclude their children from nonparental care.

\footnotetext{
${ }^{8}$ There are several reasons why the costs of childrearing should be (at least) to some extent socialized. Engster (The Heart of Justice) takes the fact that we, as children, have all appealed to other people's care to be a ground for a universal duty of care towards whoever needs it, including (other people's) children. In her book Valuing Children: Rethinking the Economics of the Family (Cambridge, Mass.: Harvard University Press, 2008), Nancy Folbre argues that parents and nonparents should share the costs of childrearing because children are akin to "public goods"-having children is necessary for social survival. I engage later in this article with Ann Alstott's argument that since raising children is such a resource-intensive activity in terms of time, money, and emotional involvement, it is unfair that parents should shoulder these costs alone.

${ }^{9}$ For example, Ingrid Robeyns has criticized the public goods argument in her review of Folbre's book in Feminist Economics 15 (2009): 116-20. Even if one accepts the premise that children are (akin to) public goods, it is not clear that this entails the socialization of childrearing costs. See, for instance, Paula Casal and Andrew Williams, "Equality of Resources and Procreative Justice," in Justin E. Burley (ed.), Dworkin and His Critics (Oxford: Blackwell, 2004), pp. 150-69.

${ }^{10}$ The list is controversial, as are the relationships between the concepts on the list.
} 
All the reasons I discuss in section 4 indicate that nonparental care advances the well-being of both children and parents by meeting some of their needs. This claim would not, on its own, make the case that nonparental care is required by justice, given the widely accepted belief that parents are free to decide what is best for themselves and, with qualifications, for their children. This is particularly true when nonparental care is one of several possibilities available to meet particular needs, as in some of the cases I discuss. A second consideration, prominent in the present article, is fairness: different arguments show that nonparental care would advance fairness towards children, and towards parents (and mothers in particular). The fairness towards parents/mothers claim depends, however, on how one answers the above question about sharing the costs of childcare. Fairness towards parents alone would not mean that nonparental care should be universal and mandatory - since parents may waive their claim to fair treatment-but rather that it should be easily available to all children, possibly at general expense.

Therefore, the most important of the fairness-based arguments is that fairness requires us to spread the risk, and limit the damage, that failed care entails for children. If true, this is a strong reason to ensure that all children receive some nonparental care. In spite of the importance we place on fairness, however, sometimes we think that what is fair does not always coincide with what is just. In the case of childcare, some individual prerogatives, such as parental rights, might limit the pursuit of fairness. To meet this objection, I advance an additional argument: I argue that children's dependence on their caregivers and the inherently asymmetrical and unequal relationships between children and caregivers generate a duty to diversify caregivers. Even if all parents were able to provide sufficient care, we would still have a duty to expose all children to some nonparental care as a way of avoiding monopolies of care and limiting children's vulnerability to any of their caregivers. I conclude that parental rights should be limited by a general duty to ensure that children do not depend too much on anybody's hands-on care.

Being required by justice, universal nonparental care is, as such, mandatory. Implementation should, however, proceed very carefully. Societies vary widely in their ability to provide adequate nonparental care for all children, ${ }^{11}$ and in the levels of parental opposition to nonparental care. It is possible that, in some cases, making nonparental care mandatory may do more damage than good, since care provided in inadequate conditions can harm children. When the organization of universal, adequate nonparental care is unfeasible due to lack of resources,

\footnotetext{
${ }^{11}$ Including children with special needs, for whom adequate nonparental care might involve much higher expense.
} 
finding the necessary resources should become a political priority. When parental opposition to mandatory nonparental care risks introducing harmful disruptions into children's lives, we should not simply accept this opposition but try to persuade parents. For this reason, it is important that arguments showing that nonparental care is a matter of fairness and duty be accompanied by arguments showing that it advances children's and parents' well-being.

In my paper, some of these arguments are based on children's and parents' needs. A fundamental normative assumption I make is that fair societies ensure that everybody's essential needs are met. Moreover, when the satisfaction of needs impacts on people's (often comparative) opportunities to lead good lives, need and fairness point in the same direction, providing all the more reason to ensure that needs are properly addressed.

Children are dependent on adults' care if their needs for security, nourishment, hygiene, affection, socialization, and basic education are to be met. Since it shapes their bodies, personalities, and various abilities, the care they receive is crucial in determining their opportunities, both as children and as future adults. Parents, in turn, have their own needs (some of which qua parents), which means they should also be cared for; but, as adults, they are less dependent than children on particular individuals. A salient need of parents, which is seriously frustrated when childcare cannot be shared, is for time. Parents need some time free from the responsibility of caring for children if they are to have proper rest and the opportunity to pursue any other projects of their own. ${ }^{12}$ Equally important, parents (as well as children) need the responsibility for childcare to be divided among several persons in order to better manage the ambivalent feelings that permeate ordinary parent-child relationships. ${ }^{13}$

The issue of caring for children is central to gender fairness, since most of the work of care is still carried out by women. I agree with the vast feminist literature that explains why this is unfair to women and possibly bad for all involved (that is, for all members of society). The claim defended here, that some childcare should be done by nonparents, is backed by reasons of gender fairness. Feminists have long argued that care work should be shared between women and men. One obvious way to achieve this is through a redistribution of care work between mothers

\footnotetext{
${ }^{12}$ This point has been made, and philosophically explored, by Anne Alstott, No Exit: What Parents Owe Their Children and What Society Owes Parents (Oxford: Oxford University Press, 2004).

${ }^{13}$ I work with the assumption that both children and parents experience ambivalent feelings towards each other-which is a widely accepted thesis, based on clinical experience, in object-relation theory. By ambivalence I mean that the love that binds most parents and children is inevitably accompanied by anger, frustration, and occasionally even hatred.
} 
and fathers, a proposal to which I am fully sympathetic. However, where attempts to encourage fathers (through regulated paternal leave, for instance) to participate in more hands-on care for their children are relatively unsuccessful, institutional care is an alternative context in which men can be encouraged to carry out some of the childcare. ${ }^{14}$ It is likely that childcare will attract more men who are inclined to care for children (but who do not have the proper incentives to do so under the current social organization of care) if social norms require that some of it would be provided in adequate institutions, that it would be given a higher status than it currently has, and its quality would be acknowledged as a matter of common responsibility. ${ }^{15}$

Because the social organization of care is deeply gendered, the conflicts between the needs of children and those of caregivers often take the form of conflicts between children's and mothers' needs. Since the wellbeing of mothers and that of children are so deeply intertwined, it is tempting to ignore these conflicts, conflate children's and mothers' needs, and perhaps retreat into an idealized-and ideologicalrepresentation of selfless motherhood. The idealization of motherhood, often encountered in popular culture and even in mainstream psychotherapy, ${ }^{16}$ obliterates those needs and interests of mothers that do not serve children's own interests. I hope to avoid this idealization without falling for the complementary one, namely, the presupposition that whatever advances mothers' needs should necessarily serve children's interests. Instead, I assume that a fair society will seek institutional arrangements that minimize rather than exacerbate the conflict between mothers'/parents' and children's needs, even if this is expensive. Suppose, for example, that a society without adequate institutional care were to sharpen the conflicts between mothers'/parents' needs to pursue their

\footnotetext{
${ }^{14}$ This would of course not resolve the issues of gender justice within individual heterosexual couples. But if it is true that some sources of widespread sexist attitudes reside in children's lack of experience of caring men, then institutional care provided by men who are presumably qualified and willing to care will go some way towards a more gender-fair society. See, for instance, Jessica Benjamin, The Bonds of Love: Psychoanalysis, Feminism, and the Problem of Domination (New York: Pantheon Books, 1988).

${ }^{15}$ Research on childcare work and gender suggests that low pay is the main disincentive for men to seek and retain employment as childcare workers, especially given an enduring expectation that men be the primary breadwinners. See Claire Cameron and Peter Moss, "Literature Review since 1990 on Job Satisfaction, Quality and Aspects of Diversity in the Care Workforce. National Report-U.K.” (London: Institute of Education, University of London, 2002). This suggests that raising the status of institutional childcare is likely to attract more men than it currently does.

${ }^{16}$ For this claim, see the critical analysis recently offered by feminist psychoanalyst Rozsika Parker, in Torn in Two: The Experience of Maternal Ambivalence (London: Virago, 2005), and Wendy Hollway, in The Capacity to Care: Gender and Ethical Subjectivity (New York: Routledge, 2006).
} 
professional life and children's needs for care. Also suppose that organizing institutional childcare of an adequate standard was a more expensive option than leaving it entirely up to individual families. I assume that, other things being equal, fairness is a reason to choose the institutional arrangement that is more expensive but which makes it more likely that neither mothers'/parents' nor children's needs will be extensively sacrificed. ${ }^{17}$ This last claim might be unconvincing for those who believe that it is fair that parents support the full cost of childrearing; but the overall argument of this paper is supported by, rather than dependent on, this claim.

\section{Existing Arguments for Nonparental Care}

The recent literature on social equality, family and gender offers several, not always fully explicit, reasons for part of the childcare being provided by nonparents. To my knowledge these reasons have not yet been presented together in a systematic argument. Common to all these approaches is a relatively unproblematic perspective on quality of care issues. They assume parental care is essential if children are to develop into autonomous, properly socialized adults who can form and pursue life plans of their own; care is thus (akin to) a primary good. These approaches, however, do not make much of the fact that care can, and often does, go wrong - and do not draw any conclusions about the best way to distribute care as a result of this fact. ${ }^{18}$

\section{(Argument 1) Leveling the field}

The fact that children grow up in families poses a serious challenge to fairness: families are sites of very unequal distributions of important goods such as education and socialization. Not only do children share their parents' material condition, but they also spontaneously inherit much of their parents' way of speaking the language, and their interests in various pursuits, habits, and social relationships. Class, power, social

\footnotetext{
${ }^{17} \mathrm{I}$ can see two different reasons for this. A general reason is that in a just society everyone's basic needs will be taken into consideration (and needs for work and pursuing individual projects, as well as needs for care, are indeed basic). A second, special, reason is that mothers'/parents' needs are not as independent from those of their children as are the needs of unrelated adults. Thus, there seems to be a special kind of moral harm in social arrangements that antagonize the needs of mothers/parents and children if alternative arrangements are available: when this happens, frustrating the needs of each party involves frustrating the needs of the other party as well.

${ }^{18} \mathrm{By}$ contrast, the original arguments I offer in favor of nonparental care draw on the fact that care can easily fail. There are of course many other reasons why nonparental care is beneficial, as some of the readers of this paper have pointed out.
} 
status, and education are being passed on from one generation to the next within families. ${ }^{19}$ Even in the absence of crass social inequalities, parents' freedom to raise their children according to their own values, which is recognized and protected by liberal regimes, means that parents' impact on their children's well-being and future opportunities is very significant. ${ }^{20}$

While there are good reasons for protecting this freedom (albeit in a qualified form), there is also a strong case for providing some nonparental childcare in order to level the playing field and mitigate, if not eliminate, some of the above-mentioned inequalities. Barbara Bergmann, for instance, has argued that if some care takes place outside the family, in daycare centers, kindergartens, and schools, children are given the chance to catch up on whatever they might miss at home in terms of education, social relations, and exposure to various values and lifestyles. ${ }^{21}$ The more egalitarian these institutions are, the better they will counterbalance home-inherited inequalities. For a variety of empirical reasons, ${ }^{22}$ one can assume that publicly funded, state-regulated institutions are more likely to be egalitarian than market-run caring arrangements. This does not necessarily mean that the costs of childrearing must be shared between parents and childless people, since the necessary public funds may come from taxes paid only by parents.

On this account, universal nonparental care would rectify, or prevent the accumulation of, pre-existing unfair inequalities. This argument provides less reason for nonparental care in an already egalitarian society. ${ }^{23}$

\footnotetext{
${ }^{19}$ For an early illustration of this point, which is now widely acknowledged, see James Fishkin, Justice, Equal Opportunity and the Family (New Haven: Yale University Press, 1983).

${ }^{20}$ Various permissible actions that are part of the everyday lives of parents and children, such as reading bedtime stories, can accumulate into competitive advantage. See Harry Brighouse and Adam Swift, "Parents' Rights and the Value of the Family," Ethics 117 (2006): 80-108, and "Legitimate Parental Partiality," Philosophy \& Public Affairs 37 (2009): 43-80.

${ }^{21}$ Barbara Bergmann, Saving Our Children from Poverty: What the U.S. Can Learn from France (New York: Russell Sage Foundation, 1996).

${ }^{22}$ If childcare is organized in private, rather than public, institutions, it is more likely that parents will be able to use economic advantage to buy better care for their children, thus defeating the purpose of institutionalized care as a means of advancing a more egalitarian society.

${ }^{23}$ As Adam Swift (How Not to Be a Hypocrite: School Choice for the Morally Perplexed Parent (New York: Routledge, 2003)) and Brighouse and Swift ("Parents' Rights and the Value of the Family"; "Legitimate Parental Partiality") argue, much of the parental care that results in social and economic opportunities for children consists of inconspicuous, everyday actions, such as reading bedtime stories to one's child. Even in an egalitarian society people will presumably have different ways of parenting, leading to unequal opportunities for their children. Because choosing particular lifestyles that parents share with their children has intrinsic, and significant, value (Brighouse and
} 
It is important to be aware of the risk that particular arrangements of nonparental care might perpetuate, or exacerbate, various social divisions, including class and economic ones (in a similar way to that in which public schools have been criticized for doing so). This is more likely if parents are allowed to choose the institution their child will attend, or if children attend local care institutions in class-segregated neighborhoods. If such obstacles are not insuperable, the conclusion of this argument is that fairness towards children demands the provision of universal nonparental care.

\section{(Argument 2) Making the no-exit commitment lighter}

A second, somewhat symmetrical, argument based on distributive justice takes parents' well-being and opportunities as grounds for the provision of some care outside the home. Parents' commitment to care for their children inevitably involves serious costs in terms of time, economic opportunities, and personal autonomy. Anne Alstott argues that when they decide to parent, people make a "no exit" commitment (i.e., a commitment from which one cannot and should not depart lightly) to give significant weight to their children's interests, often putting them before their own interests, and indeed to shape their own lives such that their children's lives go well. Children's need for continuity in care means this commitment extends over many years, hence it represents a very important opportunity cost to parents. This cost can be high enough to endanger parents' autonomy.

Furthermore, having children is no longer in modern societies a source of economic benefit or an insurance that one will be cared for when ill or old. Thus parents' commitment to their children is nowadays more demanding than it has ever been, because it involves high costs and no material benefits. According to Alstott, while it is fair that parents shoulder much of the cost of rearing their children-since they have freely decided to parent-it is also fair that parents be given social support to offset some of the cost of their commitment and to protect their autonomy. Alstott suggests the introduction of a caretaker resource account for parents in the form of money to be used for childcare and parents' own education or retirement. ${ }^{24}$

Although Alstott herself does not propose this, ensuring that all par-

Swift, "Parents' Rights and the Value of the Family"), we would not want to eliminate all such differences. Thus we would have reason to organize some institutional care to offset the inequality-inducing effects of the family, even in an egalitarian society.

${ }^{24}$ The caretaker resource accounts advocated by Alstott in No Exit would be funded through taxation of both parents and nonparents, thus redistributing some of the economic costs of childrearing between the two groups. But people who decide to parent will continue to support much of the cost of parenting themselves. 
ents have access to childcare would reduce the burden of the no-exit commitment, by redistributing to parents one of the resources they are often most short of-time. ${ }^{25}$ In this case, childcare would have to be funded through universal taxation, since its aim is to redistribute some of the costs of childcare from parents to the wider society. Thus, depending on the answer to the question of who should support the costs of childcare, this is either an argument based on fairness towards parents or, at least, an argument concluding that universal childcare would be conducive to parents' well-being by meeting their need for time.

According to the no-exit argument, nonparental care is merely one of the several alternative ways in which parental commitment could and should be made lighter. Thus it is not strictly speaking an argument for nonparental care. The assumption that parental commitment should be made lighter - whether as a matter of fairness or, at least, to advance the well-being of parents by meeting some of their needs qua parents-will also play a role in the last two arguments discussed in this paper. I will argue that nonparental care is the only way of reducing the burden of guilt that often comes with parenting.

\section{(Argument 3) Advancing gender justice}

A third reason for having some nonparental care is grounded in gender fairness. In all societies, mothers bear the costs of childrearing disproportionately, forsaking career opportunities, education, and personal development to a much larger extent than men. ${ }^{26}$ Women often miss out on opportunities because they are constantly occupied with most of the hands-on care for their children due to a combination of lack of choice and an ideology of the ever-present mother. If all childcare is to be provided by parents, then at least one of the parents must forsake the opportunity to work full-time. Given the current structure of the labor market, working part-time comes with significant penalties in terms of income, benefits, intrinsic quality of work, ${ }^{27}$ and, very significantly, in terms of future prospects for good jobs and financial security in case of divorce. In practice, it is largely mothers who work part-time in order to raise

\footnotetext{
${ }^{25}$ She does not exclude it either; indeed, her book ends with the remark that there is much more that social policy could and should do to advance justice for parents by redistributing resources.

${ }^{26}$ See Nancy Fraser, “After the Family Wage,” Political Theory 22 (1994): 591-618; Janet C. Gornik and Marcia K. Meyers, Families that Work: Policies of Reconciling Parenthood and Employment (New York: Russell Sage Foundation, 2003); and Alstott, No Exit.

${ }^{27}$ Thus working part-time often makes it less likely that one will be assigned interesting, challenging, and intrinsically rewarding tasks, or that one will have the same degree of autonomy and control over one's work as full-time workers.
} 
children. If provisions were made for parents regularly to leave their children in the adequate care of other people, they would have better opportunities to organize their work and family life in gender-egalitarian ways. ${ }^{28}$

Moreover, shifting some care work away from mothers, especially if this takes the form of professional care that involves men as well as women, will give care more social recognition. Since caring has been traditionally considered a female occupation, this will in turn improve women's social standing-assuming that the majority of care work will continue to be done by women. ${ }^{29}$ If the nonparental care is provided in well-resourced institutions, the recognition gains for the caring occupations will arguably be even more significant.

This argument appeals to gender fairness: it shows that nonparental care is required because it rectifies (a) the disproportionate way in which mothers miss opportunities, and (b) the low social recognition attached to caregiving as women's work.

Both the first and the third arguments presuppose pre-existing forms of unfairness and are thus vulnerable to the objection that it would be better to eliminate unfairness directly rather than mitigate its consequences through nonparental childcare. ${ }^{30}$ In the rest of this paper, I show that there remain reasons of fairness (as well as other reasons) for having universal nonparental care even in an economically and gender-fair society.

\section{Inevitable Failings of Care}

Childcare can and very often does fail, regardless of who the caregiver is. Here I look at how easily care fails and at consequences of bad care. The otherwise rich literature on a feminist ethics of care has so far provided little exploration of the issue of bad care. ${ }^{31}$ Some theorizing of bad care is negative-one can deduce it from what different authors have to say about good care.

\footnotetext{
${ }^{28}$ See, for example, Bergmann, Saving Our Children from Poverty.

${ }^{29}$ See ibid., and Fraser, "After the Family Wage.”

${ }^{30}$ I thank John Baker for drawing my attention to this point.

${ }^{31}$ Some exceptions are Ann Dillon, "The Ethical Education of Self-Talk," in Michael S. Katz, Nel Noddings, and Kenneth A. Strike (eds.), Justice and Caring: The Search for Common Ground in Education (New York: Teachers College Press, 1999); and Nel Noddings, Starting at Home: Caring and Social Policy (Berkeley: University of California Press, 2002). I discuss the many forms and causes of failed care and how they impact on children's well-being and opportunities in Anca Gheaus, "How do Theories of Care Challenge Ideal Theories of Distributive Justice?” in Lisa Tessman (ed.), Feminist Ethics and Social and Political Philosophy: Theorizing the Non-Ideal (Dordrecht: Springer, 2009), pp.105-19.
} 
Sara Ruddick identifies three aims that parents should pursue: the physical preservation of children, fostering their psychological development, and promoting their socialization. ${ }^{32}$ This means that when parents do not manage to keep their children safe, or to help their personal development and ensure proper socialization, they are not giving sufficiently good care. In order to achieve all the goals of such care, one needs a favorable constellation of external circumstances and individual abilities. External circumstances include parents' material resources, their social status, and the institutional set-up of the caregiver's society, as well as cultural norms and expectations, which can put pressure on caregivers to prevent children's development if such development is socially unacceptable. ${ }^{33}$ But even in ideal conditions, conflicts may develop between the different aims of care. ${ }^{34}$ Since in all societies many (perhaps most) parents struggle with precarious conditions, parenting is often likely to fall short of the standards of sufficiently good care.

Regarding the individual abilities needed to ensure good care, Joan Tronto thinks that a good caregiver has to be attentive to the cared-for, responsible for her or his well-being, competent in addressing needs, and responsive to the other person's needs. ${ }^{35}$ It follows that inattentiveness, inability to take responsibility for the child's well-being, or inability to properly address the child's needs, as well as not being responsive enough to a child, will all count as failings of care. When extreme, such failings take the form of serious negligence and abuse, and constitute grounds for removing children from their parents' custody and, when possible, placing them in other people's continuous care. But most such failings are not extreme - they are very human, indeed everyday, failings to which we are all susceptible, rather than easily avoidable mistakes. There is no reason to believe that most other caregivers could avoid

\footnotetext{
${ }^{32}$ Sara Ruddick, Maternal Thinking: Towards a Politics of Peace (Boston: Beacon Press, 1989).

${ }^{33} \mathrm{An}$ extreme example is foot-binding in China, but less dramatic examples can be found in contemporary Western societies. For instance, most societies have gender expectations that make it unacceptable for boys to be as emotional as girls and for girls to be as assertive as boys. Parents who believe, as many parents do, that is it important for their children to become socially acceptable cannot help but require, or at least encourage, children to conform to gender, class, race (and so on) expectations, even when this has costs in terms of children's development.

${ }^{34}$ One example is the conflict between encouraging the child's development (for example, encouraging her to explore the world and her own limits by climbing trees) and the aim of physical preservation of the child. There is no reason to believe that one can always strike a perfect balance between too much and too little protection. For illustrations of all the points in this paragraph, see Gheaus, "How do Theories of Care Challenge Ideal Theories of Distributive Justice?”

${ }^{35}$ See Joan Tronto, Moral Boundaries: A Political Argument for an Ethic of Care (New York: Routledge, 1993).
} 
them. The everyday character of these failings does not mean that their repercussions are minor. An inability to attend to one's child's wellbeing and development that is too minor to constitute grounds for removing the child from parents' custody can make for distressed children. Some of these children may grow into adults lacking in self-confidence, curiosity, social skills, purposefulness, and many other traits that influence how well one's life goes and one's ability to make use of opportunities.

Tronto's account of good care also mentions risks of care that are specifically moral. Caregivers can be excessively paternalistic, impeding instead of promoting children's development and autonomy; they can display parochialism, that is, pay disproportionate attention to those near and dear and not enough to particularly needy strangers; and they can neglect their own needs to the extent that they become resentful and eventually unable to care. Care shapes us morally, and when it is not adequate it lays the ground for moral shortcomings. Particular forms of good, as well as bad, care tend to reproduce themselves throughout generations. ${ }^{36}$

Turning from the ethics of care to the field of developmental psychology, the requirements of sufficiently good care appear even more difficult to meet. According to British child psychologist Donald Winnicott, the first psychologist to have looked closely at the standards of sufficiently good care (in fact, he was interested only in sufficiently good mothering), the mother figure should be able to meet the child's needs and at the same time allow the necessary amount of frustration, which enables the child to develop a sense of being separate from the mother. ${ }^{37}$ The mother has to be present and protective, yet without inhibiting the child's development. She has to sometimes fail in promptly meeting the dependency needs of the child (such as the needs for food or comfort) in order to make possible the child's separation from her, which is a necessary step in achieving maturity. It seems all too easy to fall short of this ideal: too much attention given to the child can be just as bad as too little; the same can be said about control, or thinking about the child's needs. In spite of her ambivalent feelings towards her child-which Winnicott recognized and theorized-the "good-enough mother" is forever behaving benevolently, and is able to ignore her own needs in order to ensure the child's needs are being optimally met (which, again, can involve occasional frustration of the child's needs). This is indeed a highly idealized and unrealistic representation of the good-enough

\footnotetext{
${ }^{36}$ For an account of how moral subjects are being created in the context of caring, see also Virginia Held, Feminist Morality: Transforming Culture, Society and Politics (Chicago: University of Chicago Press, 1993), and Hollway, The Capacity to Care.

${ }^{37}$ Here I rely on Parker's account of Winnicott in Torn in Two.
} 
mother, as has been argued by feminist psychologists. ${ }^{38}$

In response to Winnicott's and his followers' ideal of a mother, new theories of good mothering/parenting are being developed that look at the realistic implications of the emotional ambivalence in inherent parenthood. Love for one's children motivates parents to make the very taxing commitment to raise their children well, and ensures both continuity of care and parents' striving to uphold high standards of care. But parents responsible for hands-on care can also at times hate their children even while loving them. ${ }^{39}$ Parker argues that ambivalence in parenting (experienced by both children and parents) is unavoidable: even the best parent will be unable to avoid frustrating her or his child, and even the easiest children will put frustrating and boundless demands on their parents. As such, ambivalence need not ruin caring relationships or render bad care unavoidable, especially if it is individually and socially accepted as part of what it means to parent; it does, however, increase the likelihood of failures of care. Moreover, ambivalence makes parenting particularly difficult, intense, and emotionally costly. I shall return to this point later since it constitutes a ground to avoid social isolation in childrearing. Nonparental care is beneficial as a particularly reliable (although of course not unique) way to avoid social isolation.

\section{Nonparental Care as a Response to the Risks of Care}

In this section, I advance five reasons why some childcare should be provided by nonparents, most of which are based on the various ways in which parental care can or does fail. Nonparental care mitigates the effects and spreads the risk of bad care, teaches children how to enter caring relationships with initial strangers, addresses children's structural vulnerability to their caregivers, helps children and parents contain the ambivalent feelings of the child-parent relationship, and, finally, redistributes the responsibility for care and the ensuing blame for bad care more widely. All arguments look at the well-being of children and/or parents. Arguments 4 and 6 are also arguments based on justicegrounded in children's needs and fairness to children and, respectively,

\footnotetext{
${ }^{38}$ For example, Parker, Torn in Two, and Hollway, The Capacity to Care.

${ }^{39}$ The experience of strong, ambivalent feelings in the context of parenting is a main theme in object-relations theory. See the work of Donald Winnicott and Melanie Klein reported in Parker, Torn in Two, and Hollway, The Capacity to Care (see also Parker's extensive analyses of Winnicott and Klein on ambivalence). See also the work of some authors on care, such as Ruddick, Maternal Thinking, and (auto)biographies and essays about mothering, such as Jeane Lazarre, The Mother Knot (London: Virago, 1976), and Adrienne Rich, Of Woman Born: Motherhood as Experience and Institution (London: Virago, 1977).
} 
in a duty to prevent unacceptable forms of vulnerability. They hold irrespective of whether the costs of childcare should be supported only by parents or by the entire society. By contrast, arguments 7 and 8 are issues of fairness only if one thinks that the costs of childcare (in this case, nonmaterial) should be shared by the entire society.

All arguments relying on the widespread nature of failed care presuppose that while it is possible and desirable to educate people to be better parents, the social organization of childcare should be based on the premise that parents cannot be expected to avoid failures of care. I assume that being a sufficiently good parent, like being able to create and sustain good relationships with people in general, is not only a matter of acquiring the right knowledge about the other person's needs, but also a matter of having and displaying the right emotions and character traits. Care may fail as a result of mistakes in how one thinks children should be raised, which are easy to correct through parental training. But care also fails as a result of most caregivers' flaws of character and psychological maladjustments, which are much more difficult, if indeed possible at all, to correct. There is no reason to believe that parents have either better or worse characters or that they are either better or less well adjusted than people who are not parents. If so, then the same limitations that apply to improving people in general also apply to improving people’s parenting.

\section{(Argument 4) Mitigating the effects of failed care}

Abuse and neglect, the most frequent failings of care, range over a very wide spectrum, from murder, rape, maiming, and failing to feed children and protect their physical integrity, to name-calling, the kind of bullying of children that one can observe on the streets every day, or the inability to speak to them for prolonged periods. In the worst cases, when children suffer neglect or abuse in their homes, regular attendance at institutions such as daycare centers, kindergartens, or schools makes the prompt discovery of bad home care more likely. There are, unfortunately, rather numerous such cases. ${ }^{40}$

But children who experience much less significant failings of care would also benefit from receiving some care from nonparents. Care will fail sometimes, no matter who provides it. Examples of such failures include not being able to pay enough attention to the child's needs, insufficient patience, underprotecting or overprotecting the child, projection of one's own fears and needs onto one's child, and overburdening the child with caregivers' expectations. Caregivers' flawed relational patterns are

\footnotetext{
${ }^{40}$ According to Adams, in 2002 "[o]n a national level, more than 3 million victims of alleged abuse were reported to Child Protective Services in the whole United States" (Adams, Jusstice for Children, p.118).
} 
likely to be passed on to children. ${ }^{41}$ And it is extremely unlikely that a caregiver can always resist even minor abuses of the enormous power over children that they have as adults-particularly since caregivers are generally under the strain of meeting competing needs and interests.

There is, of course, no reason to believe that nonparental caregivers will not make mistakes. But providing a diversity of caregivers for children - without depriving them of parents — can, it is to be hoped, mitigate the unfortunate consequences of bad care, because different caregivers are likely to make different mistakes. For example, a child who is constantly made to feel stupid at home might discover, in the context of institutional care, that she can be seen as clever. In the same context, however, she might be made to feel too slow by, say, a caregiver who is unable to cope with the pace of this particular child. Experiencing mistakes in care that are different from those experienced at home may provide children with a very welcome critical distance (either immediately or, at least later on, when they develop enough skills to reflect on their own upbringing). Exposure to a diversity of caring styles and mistakes puts children in a better position to understand what is going on (i.e., flawed relational patterns), what is going wrong (i.e., that it is not one's own fault) and perhaps to summon the necessary capacities to minimize the damage (starting with the understanding that things can be different). If it is true that some of the failures that make for less than adequate care run in families and are spontaneously reproduced, then people are likely to find it difficult even to be aware of them, and likely instead to perceive those harmful patterns of interaction as normal. The most effective way to understand that things can be different is actually to experience them differently, even if the experience of care by nonparents is itself not free of failure. A child who is subjected to too much control at home, for example, might only come to understand this while being in the care of a non-controlling adult (who, in turn, might be slightly too easygoing). While it is possible that parental and nonparental caregivers will make the same mistakes, this is not very likely, especially if nonparental caregivers are trained to identify and rectify the most typical parental mistakes.

I suggest that we accept the failings of parenting as the expected and understandable shortcomings of imperfect human beings, and that we acknowledge a duty to mitigate them. An obvious way to do this is by organizing society so that children have several caregivers, who, if inevitably imperfect, can at least be expected to have different shortcomings. It is probable that professionally trained individuals will be less likely to

\footnotetext{
${ }^{41}$ See Gheaus, "How do Theories of Care Challenge Ideal Theories of Distributive Justice?”
} 
make serious mistakes in care, and will be more likely to notice and correct the mistakes made by parents; this suggests that nonparental care should take place in institutions staffed by professionally trained childcarers.

So far the argument has shown that nonparental care would contribute to children's well-being by meeting their need for sufficiently good care. Given the importance of this need, receiving nonparental care may amount to a matter of justice if the above conjectures about the widespread nature of failed care are sound. In the absence of enough empirical research, the question remains, however, whether failed care is as widespread as I suggest in this paper. If it is not, universal nonparental care can be bad for some children whose parental care is adequate and who may be exposed to more bad care overall if they are forced to receive nonparental care. Let me now address this worry.

For those readers who remain unconvinced of the widespread nature of failed care, the present argument can be cast as a prioritarian argument, centered on fairness towards the worst off. For the sake of the argument, let us assume that some children's parents are so unlikely to make any mistakes that their children would indeed be better off receiving care exclusively from their parents. With respect to parental care, these are the best-off children. By contrast, other children would benefit from getting some professional care in institutions, to correct the more or less serious failings of care from their parents. These children are worse off with respect to parental care than the first group. And a number of children, who have particularly bad parents, and who are the worst off with respect to parental care, would also benefit from receiving nonparental childcare, which would make excessively bad parental care more easily discoverable.

Moreover, suppose that reasons of privacy and the stigma attached to being (perceived as) an inadequate parent prevent us from learning who are the sufficiently good parents and who are not. The variety and speed of change of people's (including professionals') ideas of what makes a sufficiently good parent give additional grounds for not wanting to publicly label most parents as either "sufficiently good" or "inadequate." With respect to the excessively bad parents, we learn about cases of extreme child neglect or abuse too late to prevent irreversible damage. In this case, there is a prioritarian reason to create a mandatory universal system that will expose all children to some nonparental care, because this would target, and improve, the lives of the worst-off children with respect to care. This prioritarian argument is distinct from, but consistent with and similar to, the leveling-the-field argument in section 2 above. It shows that spreading the risk of bad care through universal nonparental care is a matter of fairness to children because it improves the care of the 
children who are worst off with respect to parental care.

To conclude, this is an argument of justice towards children, based on the importance of meeting their need for care and on the concern for the worst off in terms of parental care. It demands that we minimize the harms and spread the risk of failed care through universal nonparental care. This care can be provided either at the sole expense of parents or at general expense. If it is true that limitations on improving people (as parents) are irremovable, universal nonparental care will be required even in economically and gender-fair societies. Hence the relevance of this argument is wider than that of arguments 1 and 3 above, which presupposed a background of either economic or gender unfairness. The following two arguments hold, even if everybody would make a sufficiently good parent.

\section{(Argument 5) Teaching children how to create caring relationships with initial strangers}

Independent of the quality of parental care, spending some time in nonparental care that is well-designed to cater to their needs can be particularly beneficial for children. In the right setting, nonparental care gives children a chance to form intimate and trustful bonds with people who are initially strangers to them. This might be the first and critical step in developing a sense that they are part of a potentially good and trustworthy world-rather than part of a world sharply divided between benevolent family members and indifferent, or even frightening, strangers. Children benefit from having several people to care for them, not least because an ability to build and maintain caring relationships with people who are initially strangers to them is essential throughout their lives. After all, most relationships over the course of one's life are of this kind.

Research shows that in care institutions, insecurely attached children from ages two to three onwards tend to develop a close relationship with a care worker or teacher, which mitigates the effects of the initially insecure attachment. ${ }^{42}$ And there is some evidence that children in institutional childcare are better at relating to other children. According to a study on the effects of daycare on children aged 3.5 to 29 months, the significant difference between children raised at home and those who attended daycare was the latter's ability to relate less fearfully with peers. ${ }^{43}$ Therefore it is plausible that adequate nonparental care improves

\footnotetext{
${ }^{42}$ See Ross Thompson, "Early Sociopersonality Development," in William Damon and Nancy Eisenberg (eds.), Handbook of Child Psychology. Volume Three: Social, Emotional and Personality Development (New York: Wiley, 1998), pp. 25-104.

${ }^{43}$ See Jerome Kagan, Richard B. Kearsley, and Philip R. Zelazo, "The Effects of Infant Day Care on Psychological Development,” Evaluation Review 1 (1977): 109-42. See
} 
general relational abilities.

This argument shows that nonparental care can advance children's well-being in a way that is also morally very significant, because it helps create a more caring and trustful society. Even if on its own it does not make a case for a universal system of nonparental care, this conclusion lends important support to such a system.

\section{(Argument 6) Addressing children's inherent vulnerability}

The claim that significant failures of care are the rule rather than the exception is difficult to prove, not least because it is difficult to trace such mistakes without invading people's privacy. Furthermore, both as children and as parents we have strong psychological interests in denying, or quickly forgetting, these failures (although at times we become intensely aware of them).

But there is an argument related to mistakes in care that is independent of the actual extent of bad care. In a nutshell, the argument is: children are highly vulnerable to their caregivers. For this reason, the relationships between caregivers and children are structurally asymmetrical and unequal in power. Such relationships are unacceptable if they involve monopoly. Hence there is a duty to ensure that children have several independent caregivers, even if caregivers' failings were merely possible, rather than actual.

Robert Goodin's analysis of vulnerability and unacceptable relationships of dependence ${ }^{44}$ is very relevant to questions regarding duties towards children, although, to the best of my knowledge, he does not apply it himself to these issues. It is clear that children are what Goodin calls "disjunctively vulnerable" to adults as a group in their need for care, which, in theory, they could receive from any adult from a given collectivity.

Goodin argues that vulnerability singles out individuals as recipients of special obligations: people to whom individuals are vulnerable, either individually or collectively, have the obligation to attend to the wellbeing of the vulnerable. Vulnerability can be to individual persons, but also to groups, and one way of being vulnerable to groups is by being vulnerable to any of the members of the group for the needed assistance (disjunctive vulnerability). According to Goodin, when someone is vulnerable to a group, the respective group has a duty to coordinate efforts in order to ensure that the vulnerable individual will be properly treated. Thus the organization of care-that is, ensuring that children are adequately cared for, and deciding on standards of care, including the ques-

also Waldfogel, What Children Need.

${ }^{44}$ See Goodin, Protecting the Vulnerable. 
tion of who has the responsibility to perform which kind of care towards children-is a matter of social responsibility.

For reasons of efficiency, and because children need continuity in care, society assigns the main responsibility for children to particular individuals - usually to their natural parents. But it is not acceptable to assign the entire responsibility for childcare to single individuals or families. If childcare is entirely confined to any particular individual, or even to a family of individuals, the relationship between children and their caregivers is objectionable. In his analysis of vulnerability as a ground for moral obligation, Goodin addresses the question whether vulnerability and dependency are in themselves morally objectionable and claims that, in many situations, they need not be. Relationships involving vulnerability are morally objectionable only if they involve the following characteristics: (a) they embody an asymmetrical balance of power; (b) the less powerful party vitally needs whatever the other party is supplying; (c) the more powerful party is the only supplier of what the other party needs; and (d) the more powerful party has discretionary control over those resources. ${ }^{45}$ Relationships between children and parents fit perfectly the first two features of the model: they are asymmetrical relationships in which parents give vitally needed care to their children. If parents are the only source of regular and reliable care for their children, then the relationship acquires the third and fourth features, thus making it, according to Goodin's theory, morally unacceptable.

Many societies have legislation and child protection institutions that allow intervention in the parent-child relationship where parental power is abused, thus making sure, in theory, that the fourth condition does not apply. However, these precautions are insufficient, since abuses of parental power are difficult to detect and even more difficult to prevent, as we know from the history of physical abuses discovered when the damage had already been done. When abuses of power, or the mere inability to supply the needed care, are psychological and moral rather than straightforwardly physical, they are even more difficult to discover and redress.

Note that Goodin's theory of monopolist dependency relationships means that they are wrong even if no abuse takes place. As long as the less powerful party (here, children) cannot withdraw from the relationship without severe costs (as, clearly, children cannot), the relationship is deemed morally unacceptable. ${ }^{46}$

Providing nonparental care as a regular complement to parental care is the least we can do to loosen the parental monopoly on care for each child and thus take steps towards containing the high risks of such mo-

\footnotetext{
${ }^{45}$ Goodin, Protecting the Vulnerable, p. 195.

${ }^{46}$ See, in particular, Goodin, Protecting the Vulnerable, pp. 196-202.
} 
nopoly. For this solution to work, the nonparental care would have to be a robust source of care: reliable, regular, professional, and coming from people or institutions that are independent of parents - to ensure that should parental care fail, the child can safely turn to the nonparental caregiver for help. In practice, this would mean that childcare institutions be ready to give children a default, even if temporary, alternative to family care. ${ }^{47}$

In many cases of failed parental care, nonparental care will not lead to institutionalizing children fully or to placing them in other homes. Rather, it will be a source of supplementary care, making children less dependent on parental care. A small child whose slow development baffles his family to the point of giving up on him would be treated with the necessary patience by properly trained daycare staff-which could not happen if the child did not attend daycare. A teenager who does not receive the guidance she needs at home could turn to the school psychologist - which she could not do if she were, for example, homeschooled, or if schools were strictly academic institutions. Exposure to nonparental care would not only mitigate the damages of failed care, but it would also render the children's vulnerability to their caregivers morally more acceptable.

Strictly speaking, this argument suggests that responsibility for children should be shared between parents and other people from the moment of birth. However, if the evidence that children under one year old need the continuous presence of one of their parents, and that nonparental care before age one may be damaging, is sound, there is a strong argument against universal nonparental care before that age. (Or, at least, against institutional nonparental care; other types of nonparental care, such as universal and mandatory home visits from childcare workers, may be warranted.)

This is an argument to the effect that provision of high-quality childcare should be acknowledged as a matter of common responsibility and that even if all parents were able to give sufficiently good care, there would still be a duty to expose all children to some nonparental care. Since providing nonparental care for all children is the best way of addressing the unacceptable vulnerability to a unique source of care, we should ensure that all children receive some nonparental care. This is a strong argument for understanding nonparental care as a matter of justice, based on the duty to protect children from unacceptable vul-

\footnotetext{
${ }^{47}$ According to a recent article in the New York Times (Ian Urbina, "For Runaways, Sex Buys Survival," 27 October 2009), there are 1.6 million runaway children each year in the United States, many of whom never return to their families but end up in the underworld of drugs and prostitution. While there is some institutional space for accommodating these children, it is not sufficient and not offered as a default option.
} 
nerabilities, and thus for introducing compulsory universal nonparental care.

\section{(Argument 7) Containing the ambivalent emotions of parenting}

The next argument is grounded in the well-being of both parents and children, and starts from the assumption that ambivalence is a constant of the intimate relationship between parents and children. ${ }^{48}$ There is a vast feminist literature that analyzes the harms of over-idealized representations of mothers as having entirely loving feelings for their children; ${ }^{49}$ arguably the same applies to over-idealized representations of parenthood. Ambivalent feelings towards one's child are particularly difficult for parents who raise their children in relative social isolation and who bear the responsibility of hands-on caring for them alone. The social isolation of a parent continuously caring for her child increases the intensity of parenting and exacerbates maternal/parental ambivalence..$^{50}$ Nonparental care is one reliable way to break this continuity periodically and safely and to give parents the necessary parenting-free time.

Once ambivalence and the danger of social isolation are recognized, it may be easier to acknowledge the importance of sharing the intense work of childcare between several people. ${ }^{51}$ Although inevitable, the intensity resulting from parents' and children's ambivalence can be made more bearable, and less harmful, if parental childcare is periodically interrupted by nonparental care. Sharing with other caregivers the burden of being seen at times as horrible can be beneficial for parents and actually promote better parenting. The mutually aggressive emotions that are part of the relationships between parents and children are more likely to be kept in check and managed if the bond of care is not exclusive, but alongside the parent there are other-ideally committed and fairly continuous-caregivers. Thus some nonparental care would advance the well-being of both children and parents because it would mitigate the

\footnotetext{
${ }^{48}$ In psychological theory informed by clinical practice, this was first theorized by Winnicott and Klein. For recent work on parental ambivalence see also Parker, Torn in Two, and Wendy Hollway and Brid Featherstone (eds.), Mothering and Ambivalence (New York: Routledge, 1997).

${ }^{49}$ See Benjamin, The Bonds of Love; Ruddick, Maternal Thinking; Parker, Torn in Two.

${ }^{50}$ Parker's work abounds in examples of mothers who, being the only continuous caregivers of their children, struggle not only with the frustration of experiencing ambivalence, but also with the fear of acting on their aggressive feelings.

${ }^{51}$ Benjamin argues that the sentimental idealization of motherhood and denial of motherly ambivalence impedes change in the provision of better day care, medical care, maternity leave, and flextime in the workplace, which are so necessary for real, imperfect mothers and unnecessary for the ideal, omnipotent ones (Benjamin, The Bonds of Love, p. 211).
} 
extent and consequences of ambivalence.

This argument, as well as the following, are similar in structure to the second argument discussed in section 2, namely, that we should advance parents' well-being by organizing childcare such that parents share with others some of the (material and nonmaterial) costs of rearing children. If ambivalence-with the intense, and sometimes aggressive, emotions it entails - is a burden, then mitigating parental ambivalence is also good for children. Parents might still be the ones most emotionally involved, for better or worse, with their children. But if other people regularly take on some of the work and responsibility of caring for children, parenthood does not have to be the disproportionately resource-demanding activity it is if undertaken by parents alone.

Whether this is also a matter of fairness to parents is more controversial. As more generally in this paper, I do not take into consideration the benefits of parenthood. Some readers will think that once we take these benefits into account, we shall find it is only fair that parents shoulder alone the entire burden of having children. They will resist the conclusion that alleviating the burdens of the no-exit commitment-in the form it takes in Alstott's argument that I presented above, and in arguments 7 and 8-is a matter of fairness to parents. But they will not resist the conclusion that alleviating the burdens of ambivalence (and, in the next argument, of blame) is beneficial and that nonparental care-at parents' expense-is an obvious solution, given the various benefits it has for children. Moreover, if the burdens of children's own ambivalence and resentment (see below) about bad care are indeed both inevitable and serious realities that nonparental care could alleviate, there may be a case of fairness towards children in favor of universal nonparental care (whether at parents' or at everybody's expense). This would of course require a significant amount of empirical support and additional argument.

\section{(Argument 8) Redistributing the blame for bad care}

In addition to the harm it inflicts on children, and the guilt it inflicts on parents, failed care entails long-lasting blame. Because the care one receives early in life shapes one's personality, character, and long-term prospects, people can harbor deep resentment against their caregivers for their failings and mistakes.

Blame against mothers is widespread across different societies, and is present in cultural representations, such as folklore and everyday humor, in medical and psychological theory and practice, and in legal practice. ${ }^{52}$

\footnotetext{
${ }^{52}$ For blame against mothers in everyday circumstances, see Molly Ladd-Taylor and Lauri Umansky (eds.), "Bad" Mothers: The Politics of Blame in Twentieth-Century
} 
Blame against parents is present to a much lesser extent—unsurprisingly, since until very recently it was mothers who provided the vast majority of hands-on caring for children. It is tempting to speculate that as mothers and fathers start to share hands-on care for their children more equally, mother-blaming is being replaced by parent-blaming. Much of the existing blame is sexist, and undoubtedly much of it is misguidedfor example, we now know that conditions such as autism and schizophrenia, once blamed on inadequate mothering, have different causes.

Suppose that the kind of misguided blame present in these examples were entirely eliminated and we could correctly identify the unhappy consequences of failed care. Then it would be fair to blame some such failures-for instance, intentional and conscious cruelty-on parents. It would be less fair to blame them for other failures-such as, perhaps, unintentional, unconscious cruelty. ${ }^{53}$ But whether excusable or not, both kinds of failings might have the same impact in terms of the children's well-being and development. There is an understandable tendency for individuals to hold their parents partially accountable for their own shortcomings, whatever their causal history. If it is true that primary caregivers shape to a large extent our personalities and characters, it is hard to see how even the undeserved, or less deserved, blame for failed care can be entirely eschewed.

It is not only children who are angry about the (perceived) failings of care, but also, sometimes, third parties. Spouses for example are often resentful at what they perceive to be failings in the upbringing of their partners, and so are grandchildren or close friends if they attribute systematic relational difficulties to past bad care. Such blame outlives not only bad care and its harms, but sometimes even the caring relationships themselves, which often collapse under its pressure.

If mistakes are endemic to care, and if they result in blame that erodes some of the most important relationships, it does not seem beneficial that caregiving be socially organized such that all blame is inevitably placed

America (New York: New York University Press, 1998). For the systematic way in which psychiatrists, psychologists, and counselors blame mothers for a wide variety of their children's problems, from social and educational inadequacies to different functionings such as autism to mental troubles such as schizophrenia, see Paula Caplan and Ian Hall-McCorquodale, "Mother-Blaming in Major Clinical Journals," American Journal of Orthopsychiatry 55 (1985): 345-53; and Paula Caplan and Ian HallMcCorquodale, "The Scapegoating of Mothers: A Call for Change," American Journal of Orthopsychiatry 55 (1985): 610-13.

${ }^{53}$ Especially since collective understandings of what counts as cruel vary. Where I grew up, children have regularly witnessed much animal suffering, without there being, either amongst the adults or the children, a sense that this was cruel and that children should have been sheltered from this. Exposing children to such amounts of animal suffering would be considered cruel today in most Western countries. 
on parents. An organization of childcare that systematically results in blame being put only on parents is possibly also unfair, at least to those children who feel particularly acute resentment due to very bad care. A better arrangement would involve parents sharing with others the risk of giving bad care and the resulting blame.

If nonparents did some of the work of care, at either parents' or society's expense, they would share with parents the responsibility for its inevitable failings, which might also help to diminish the overall amount of blame in two ways. First, if nonparents provided some of the childcare, then the impact of mistakes and other failings of care would be less damaging (cf. argument 4) and thus the blame placed on parents would be diminished. Second, if several people care for us while we are children, and if this gives us a better chance of understanding their mistakes as human and to be expected, then we might be better able to resist blaming our caregivers (parental or not) for those types of failure, which are unintentional, unconscious, and common to most human beings.

Given the importance for children to have at least one parent in one's life, it is unrealistic to believe that we could, or should, try fully to share childcare, together with its endemic mistakes and the ensuing blame between parents and nonparents. And, given the intensity and strength of the bond between mothers and children, who start out as nondifferentiated bodily and psychical entities, it may be unrealistic to believe that we could, or should try to, write gender out of the distribution of very early childcare (and its unavoidable tribulations). The real choice is between allowing parents to do all the childcare and sharing some of it between parents and nonparents.

\section{Conclusions}

I have presented several existing arguments on the value of nonparental care. I then offered five more arguments, based on the observation of how difficult it is to give sufficiently good care, that we should ensure that all children are exposed to some nonparental care. Taken together, the arguments discussed here show that a social organization of care that exposes all children to some nonparental care in adequate settings would advance children's and parents' well-being, would be fair to children and possibly to parents as well, and is called for by a duty to protect children from unacceptable vulnerabilities. I have implicitly argued against the legitimacy of all types of childrearing - such as, for example, homeschooling - that tend to prevent children from creating enduring and robust care relationships with adults outside the households where they grow up. In particular, the arguments based on fairness towards children and on the duty to protect them from unacceptable forms of dependence 
lead to the conclusion that nonparental care should be universal.

Several of the arguments concerning failed care might equally support the conclusion that sharing the work between two parents is better than having all or most of it provided by only one parent, and that having more family members involved in childrearing is better than confining all childcare to the nuclear family.

Arrangements for nonparental care are already in place in many societies, but this is not the case everywhere in the world, and these arrangements are not as strongly normative as they should be. Most importantly, because it is not universal, existing nonparental care might be excluding precisely those children who are most in need of receiving it. ${ }^{54}$

\author{
Anca Gheaus \\ Philosophy Department \\ Erasmus University Rotterdam \\ agheaus@gmail.com
}

\footnotetext{
${ }^{54}$ I have presented versions of this paper within the EWI seminar series at the Equality Studies Department at University College Dublin in February 2009, the work in progress seminar organized by the practical philosophy group at the Erasmus University Rotterdam in June 2009, Priority in Practice, Dublin in June 2009, Manchester Workshops in Political Theory, Manchester Metropolitan University, September 2009, and Equality of Opportunities, Lisbon, October 2009. I am grateful for the comments and questions I received on these occasions and am particularly thankful to several people for suggestions on previous drafts of this paper: John Baker, Barbara Bergmann, Philip Cook, Jurgen de Wispelaere, Daniel Engster, Jens Hubner, Kathleen Lynch, Adina Preda, Ingrid Robeyns, Anders Schinkel, Adam Swift, Bart Van Leeuwen, Daniel Weinstock, and to two anonymous referees for Social Theory and Practice. This article was funded by an EWI Marie Curie Fellowship at the Equality Studies Department, University College Dublin and the Netherlands Organization for Scientific Research (NWO).
} 